\title{
A NEW STAINING TECHNIQUE FOR THE CANAL OF SCHLEMM AND ITS EMISSARIES* ${ }^{\dagger}$
}

\author{
BY \\ H. R. HAUSLER AND T. M. SIBAY \\ Departments of Ophthalmology and Physiology, University of Toronto, Canada
}

THE canal of Schlemm and its emissary vessels have been studied extensively by various methods. Injection of dyes (Hausler and Sibay, 1960) or corrosion cast preparations (Ashton, 1951, 1952; Ashton and Smith, 1953; Kiss, 1943; Kiss and Orbán, 1951) showed the distribution of these vessels but did not reveal structural details of their walls. In histological sections, on the other hand, only a small area of sectioned vessel could be studied and the continuity of the vascular system was lost to the observer. The present investigation was undertaken to illustrate that, with a new staining technique, the gross and histological details of the canal of Schlemm and its emissaries could be very satisfactorily studied. In a previous report it was shown that this method was very suitable for staining the cell boundaries of the retinal blood vessels (Hausler and Sibay, 1960).

\section{Material and Methods}

The material consisted of ten enucleated human eyes obtained from the Eye Bank of Ontario. Each eye was cut around its circumference, $6 \mathrm{~mm}$. posteriorly and parallel with the limbus.

The anterior portion of the eye was retained for study and the posterior portion was discarded. After the removal of the lens and the iris, the specimen was bisected through the centre of the cornea to expose the canal of Schlemm. The tissue was then fixed on blocks of plasticine with the cut surface uppermost. With the aid of a dissecting microscope, a fine glass cannula (or fine-gauge needle, No. 30) was inserted directly into the canal of Schlemm. The canal of Schlemm was washed first with saline and then with 10 per cent. formalin solution. A freshly prepared silver solution, consisting of 2 per cent. "silver dinaphthylmethane disulphonateł", was injected through the same needle. The injected specimen was put in a dish containing glycerine to clear the tissue and then exposed to ultra-violet light for 2 to 3 minutes till a brownish colour appeared.

* Received for publication December 8, 1960.

+ These studies were carried out under a National Health Research Grant.

This paper was presented at the East-Central Section meeting of the Association for Research in Ophthalmology, Ann Arbor, Michigan, 1960 .

‡ Commercially available as "Viacutan” produced by Ward Blenkinsop \& Co., 6 Henrietta Place, London, W.1. 
The trabecular wall of the canal of Schlemm was cut as a ribbon-like strip with a fragment of a razor blade under a dissecting microscope. This tissue was then removed and mounted in glycerine on glass slides for histological examination. The rest of the specimen containing the scleral wall of the canal of Schlemm was kept in glycerine and studied microscopically.

\section{Results}

Details of the endothelium of the scleral wall of the canal of Schlemm are seen in Fig. 1, which shows the opening of one of the many emissary vessels.

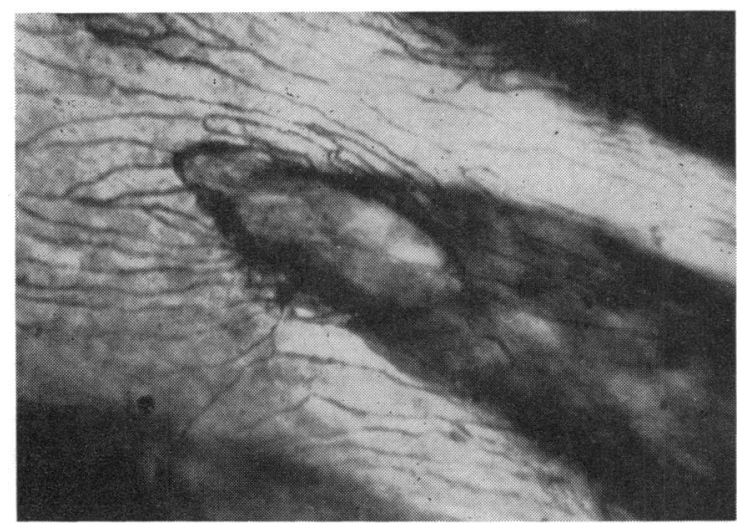

FIG. 1.-Opening of one of the emissary vessels from the scleral wall of the canal.

The scleral wall of the canal was found to be lined by an endothelium of elongated spindle-shaped cells, their long axis being mostly parallel with the axis of the canal. This pattern had been interrupted around the openings of the emissary vessels where the endothelial cells assumed a more irregular shape. The emissary vessels, after emerging from the canal, divided up immediately into a dense intra-scleral plexus where they freely anastomosed with one another (Fig. 2).

FIG. 2.-Emissary vessels within the sclera forming a meshwork shortly after leaving the canal.

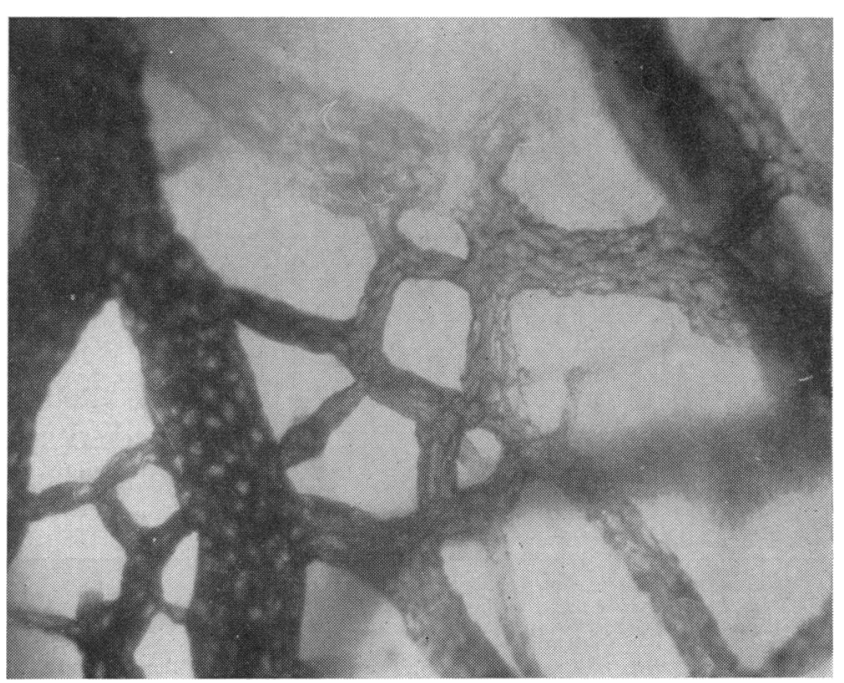


The irregularity in the shape and calibre of these vessels was striking (Fig. 3). They were lined by endothelial cells which were wider and not so elongated as those lining the scleral wall of the canal of Schlemm. A few emissary vessels showed a fairly straight course through the sclera to the episcleral and conjunctival plexuses. These vessels might correspond to what is clinically seen as aqueous veins.

FIG. 3.-Emissary vessels within the sclera showing the outline of endothelial cells.

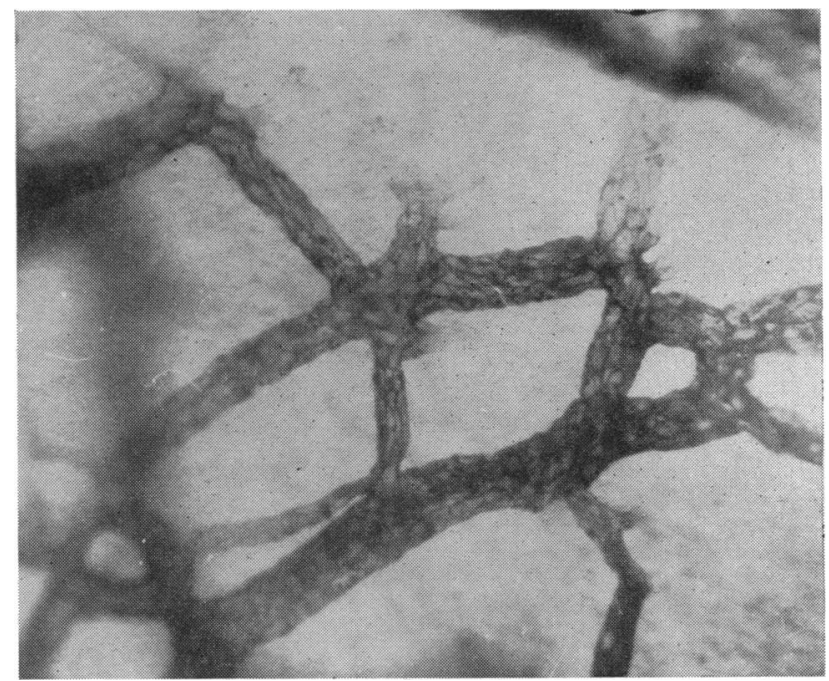

Fig. 4, and Fig. 5 (overleaf), show the structural details of the trabecular wall of the canal of Schlemm. The endothelium consisted of spindle-shaped cells of variable size. The long axis of these cells frequently lay at an oblique or right angle to the axis of the canal and occasionally the cells were arranged in a whorl-like pattern. Although the trabecular wall gave the impression of a solid membrane, a number of small stomata could be seen between some of the endothelial cells, usually located at their apices.

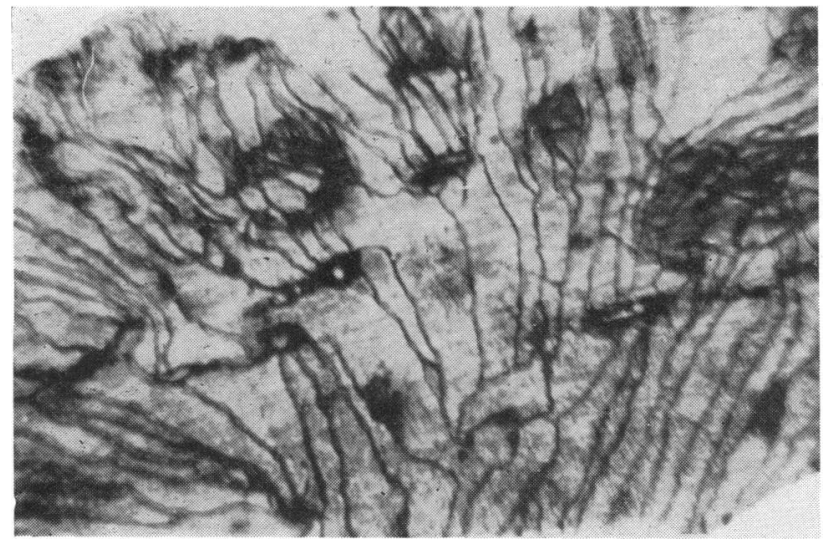

Fig. 4.-Structural details of the trabecular wall of the canal. 


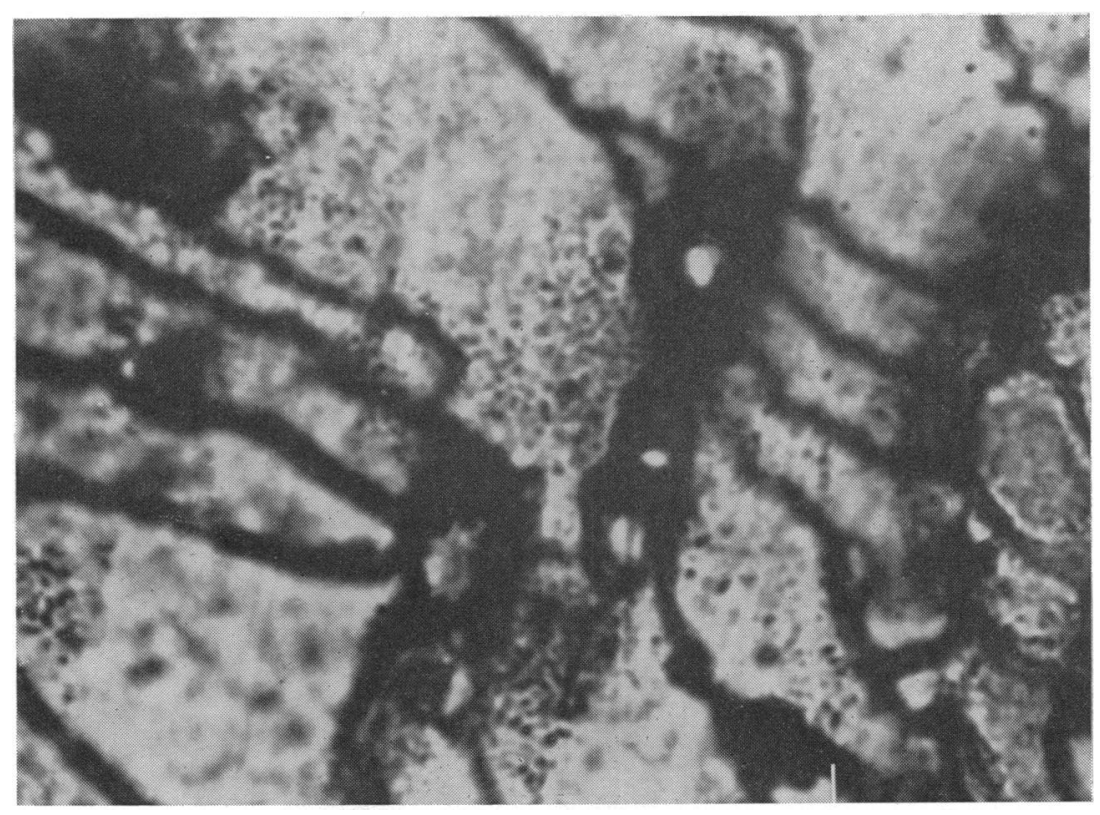

FIG. 5.-Endothelium lining the trabecular wall of the canal. A number of stomata are seen between the endothelial cells.

\section{Summary}

A new staining technique is described which has been found very satisfactory for demonstrating the boundaries of the endothelial cells of the canal of Schlemm and its emissaries.

\section{REFERENCES}

AsHton, N. (1951). Brit. J. Ophthal., 35, 291.

(1952). Ibid., 36, 265.

and SMITH, R. (1953). Ibid., 37, 577.

Hausler, H. R., and Sibay, T. M. (1960). Ibid., 44, 46.

KISS, F. (1943). Ophthalmologica (Basel), 106, 225.

and Orbán, T. (1951). Acta morph. Acad. Sci. Hung., 1, 23. 